\title{
O palácio da memória, ou: da arte de contar histórias
}

\author{
The memory palace, or: the art of storytelling \\ El palacio de la memoria, o: del arte de contar historias
}

José Douglas Alves dos Santos ${ }^{1 *}$

${ }^{1}$ Universidade Federal de Santa Catarina, Santa Catarina, Brasil.

Dimeo, Nate. O palácio da memória. Tradução de Caetano W. Galindo. 1. edição. São Paulo: Todavia, 2017. 256 p.

\section{O palácio da memória, de Nate DiMeo} (Todavia, 2017), pode ser descrito como uma obra de caráter transdisciplinar, no âmbito acadêmico-escolar — como leitura obrigatória em aulas relacionadas à História e/ou ao Ensino de História, bem como à escrita ou processos de escrita, tanto no ensino superior como na educação básica - e para além dele - como uma leitura não obrigatória, selecionada sem uma finalidade pedagógica específica.

$O$ fato de se enquadrar de modo peculiar nesses dois espaços formativos que muitas vezes parecem tăo distantes um do outro (o acadêmico-escolar, com suas normas e saberes sistematizados, e o do cotidiano, que não estabelece uma rotina tăo rígida e apresenta outra relação com os saberes, na sua transmissáo e recepção) possibilita ao livro de DiMeo algo que poucas obras conseguem: articular o saber histórico formal com o saber histórico do dia a dia.

Seja para amantes da História ou de histórias, $O$ palácio da memória traz registros históricos contundentes, utilizando uma narrativa autoral que faz da leitura uma experiência no mínimo singular e recomendável.

Nate DiMeo, natural de Providence, em Rhode Island, nos Estados Unidos, é um ex-músico que trabalhou como repórter de rádio por mais de dez décadas, segundo relata Fernanda Ezabella (2017), que realizou uma entrevista com o autor antes de a obra chegar às livrarias brasileiras. ${ }^{1}$ Nessa entrevista ele explica seu interesse por temas relacionados ao século XIX, ou, mais especificamente, aos anos entre 1880 e 1920 , período em que "a vida moderna estava sendo inventada", como afirma.

1 EZABELLA, Fernanda. Ex-repórter de rádio, Nate Dimeo cria podcast que vai virar livro no Brasil. Folha, Los Angeles, 30 de julho de 2017. Disponível em: http://wwwl.folha.uol.com.br/ serafina/2017/08/1904465-ex-reporter-de-radio-nate-dimeo-cria-podcast-que-vai-virar-livro-no-brasil. shtml. Acesso em: abril 2018.

DOI: http://dx.doi.org/10.1590/2237-101X020041011

Resenha recebida em 14 de maio de 2018 e aceita para publicação em 28 de agosto de 2018.

* Doutorando da Universidade Federal de Santa Catarina/Centro de Ciências da Educaçáo, Programa de Pós-Graduação em Educação, Florianópolis/SC - Brasil. E-mail: jdneo@hotmail.com. ORCID: https://orcid.org/0000-0002-7263-4657. 
É diante do excesso de informação de nossa cultura contemporânea - descrito desde a primeira metade do século passado por Walter Benjamin, ${ }^{2}$ salientado por Ítalo Calvino ${ }^{3}$ na metade da década de 1980 e também por Georges Balandier ${ }^{4}$ no final daquela época - que DiMeo encontra seus personagens e constrói (ou tenta reconstruir, a partir da perspectiva histórica) suas histórias. Diante desse excesso algo sempre surge lhe chamando a atenção, fazendo-o voltar posteriormente para checar a veracidade e pesquisar em museus e arquivos de jornais, para em seguida pensar sobre a forma de contar mais uma de suas histórias.

O que impressiona em seu trabalho, realizado desde 2008, quando estreou o podcast "The Memory Palace", 5 é a sua capacidade de contar histórias e de demonstrar suas potencialidades, bem como a força dessa prática por vezes tão esquecida em nossa era digital-informativa, em que muitas vezes a multiplicidade midiática retira nosso tempo de reflexão sobre determinado conteúdo, nos privando da "riqueza de significados possíveis", como expressou Ítalo Calvino, pois a superabundância de imagens e de informaçôes muitas vezes "se dissolve imediatamente como os sonhos que não deixam traços na memória”. ${ }^{6}$

\footnotetext{
${ }^{2}$ BENJAMIN, Walter. Magia e técnica, arte e politi$c a$ : ensaios sobre literatura e história da cultura. São Paulo: Brasiliense, 2012. (Obras Escolhidas, v. 1)

${ }^{3}$ CALVINO, Italo. Seis propostas para o próximo milênio: lições americanas. São Paulo: Companhia das Letras, 1990.

${ }^{4}$ BALANDIER, Georges. O dédalo: para finalizar o século XX. Rio de Janeiro: Bertrand Brasil, 1999.

${ }^{5}$ Que pode ser conferido em: http://thememorypalace.us/.

${ }^{6}$ CALVINO, Italo. Seis propostas para o próximo mi-
}

Mas é da adversidade que conseguimos enxergar e criar alternativas, como analisa Marcelo Yuka. ${ }^{7}$ Nesse sentido, Nate utiliza desse excesso de informaçáo para pegar aquilo que lhe toca e trabalhar em cima do que foi selecionado com a prudência e o cuidado de um historiador de ofício, dando o seu devido tempo e atenção. Desse modo, ele consegue deixar muitos traços das memórias que narra em nossas mentes-corpos - uma vez que estes são elementos indissociáveis de nossa percepçáo sensorial do mundo - , nos atingindo física e emocionalmente diante de seus relatos.

Se Georges Balandier (1999) ressaltava sobre o processo de banalizaçáo e de sobrecarga do imaginário social por meio da constante repetiçáo de imagens e informações sem uma orientação crítica de seus usos, temos em $O$ palácio da memória uma experiência muito diferente. Experiência, a propósito do ato de narrar, de contar histórias surpreendentes, que Walter Benjamim afirmava, em 1936, ser uma arte em vias de extinção. ${ }^{8}$ Segundo o filósofo alemão:

São cada vez mais raras as pessoas que sabem narrar devidamente. É cada vez mais frequente que, quando o desejo de ouvir

lênio: liçôes americanas. op. cit. p. 73.

${ }^{7}$ YUKA, Marcelo. Sua relação especial com o corpo. TEDxSudeste, 30 out. 2010. Disponível em: https:// www.youtube.com/watch?v=WLIN_Xf4CFk. Acesso em: abril 2018.

${ }^{8}$ É importante situar que o contexto histórico em que Benjamin escreve sobre experiência é o do período entre guerras (Primeira e Segunda Guerra Mundial), quando os soldados voltavam dos campos de batalhas sem conseguir narrar sobre o que acontecera, afetando-os de modo permanente. 
uma história é manifestado, o embaraço se generalize. É como se estivéssemos sendo privados de uma faculdade que nos parecia totalmente segura e inalienável: a faculdade de intercambiar experiências. ${ }^{9}$

Essa crise no ato de contar histórias, de intercambiar experiências significativas, é justificada por Benjamin ao afirmar que os fatos reportados em sua época, vindos de todas as partes do mundo, não favoreciam a narrativa - a experiência da narrativa -, pois vinham impregnados de explicaçôes sem a necessidade da escuta atenta e sensível, do processo de efetuar relaçóes e de refletir sobre o ocorrido; em contrapartida, isso favorecia o excesso de informação, que ainda hoje é um dos temas mais abordados por pesquisadores em diferentes áreas e campos do saber, como História, Educação, Sociologia, Comunicação, Mídia, Filosofia, Cinema, entre outros.

E por que a leitura de $O$ palácio da memória é uma experiência narrativa diferenciada? Justamente porque Nate DiMeo consegue manifestar nosso desejo de ler/ouvir histórias, servindo como antídoto a todo o excedente informativo que permeia nossos dispositivos móveis e nossas vidas. Não obstante, ele demonstra que a História, deveras considerada um peso sem significado aparente na vida de muitos jovens estudantes, pode sim ser mais atrativa e carregada dos mais diversos significados.

\footnotetext{
${ }^{9}$ BENJAMIN, Walter, Magia e técnica, arte e politi$c a$ : ensaios sobre literatura e história da cultura, op. cit., p. 213.
}

Este é outro grande mérito desse artista estadunidense, de nos instigar — professores/formadores da educação básica ou do ensino superior - a rever nossos métodos e nossas próprias práticas pedagógicas, a ponto de podermos utilizar $O$ palácio da memória em nossas aulas como um ponto de partida, um meio para elaborar novas possibilidades de ensino, de envolver nossos alunos com os conteúdos curriculares prescritos institucionalmente.

Não há outro meio de se conhecer mais a História e seus acontecimentos se não mergulhando naquilo que ela tem a nos oferecer. DiMeo faz isso, ele mergulha nas histórias que nos conta de modo a se aproximar das práticas relativas aos historiadores que atuam no campo da História Oral, contribuindo nesse terreno do "estudo da subjetividade e das representaçóes do passado tomados como dados objetivos, capazes de incidir (de agir, portanto), sobre a realidade e sobre nosso entendimento do passado", como sintetiza Verena Alberti ${ }^{10}$ a respeito dessa metodologia e abordagem historiográfica.

Essa aproximação com a História Oral está presente ao longo de toda obra, quando Nate toma como protagonistas de muitas de suas histórias sujeitos/personagens "comuns", de "carne e osso" como todos nós, que não fazem parte daquela História seletiva e oficial - ou por muito tempo oficializa$\mathrm{da}$ - que costumamos aprender nos bancos escolares, mas que, de acordo com Lucília

\footnotetext{
${ }^{10}$ ALBERTI, Verena. O lugar da história oral: o fascínio do vivido e as possibilidades de pesquisa. In: ALBERTI, Verena. Ouvir contar: textos em história oral. Rio de Janeiro: Editora FGV, 2004. p. 13-43. p. 10.
} 
Delgado, ${ }^{11}$ "anônima ou publicamente deixam sua marca, visível ou invisível, no tempo em que vivem, no cotidiano de seus países e também na história da humanidade".

Há também algumas grandes figuras conhecidas da História, sobretudo da história estadunidense, onde se passam as narrativas; mas nem por isso perdem seu valor, pois, quando contextualizados com a história social e coletiva da humanidade, conseguimos identificar sua importância e até mesmo relacionar a equivalentes de nossa própria esfera sociocultural.

Alguns desses nomes são de indivíduos que se consagraram em seus respectivos campos de atuação. Todavia, não se busca enaltecer e divinizar, nem tampouco condenar e demonizar tais sujeitos. Suas histórias são transcritas a partir de um contexto histórico-cultural maior, no qual o que importa, no fim das contas, náo é reconhecer aqueles considerados e tratados como protagonistas, e sim ter consciência de que a história contada, por si só, teve (e, de certa maneira, continua tendo) uma relevância suficientemente expressiva em determinado tempo e espaço onde elas aconteceram - na verdade para além disso, uma vez que muitas delas cruzaram oceanos e continentes, inscrevendo-se na narrativa da história humana.

O palácio da memória está estruturado em 50 breves narrativas que abordam desde as desventuras de Samuel Finley Breese

11 DELGADO, Lucília de Almeida Neves. Memória e história: multiplicidade e singularidade na construção do documento oral. Cadernos CERU, série 2, n. 12, p. 23-30, 2001. p. 24. Disponível em: https://www.revistas.usp.br/ceru/article/ view/75083/78649. Acesso em: março 2018.
Morse - que, após perder a esposa e sequer conseguir estar presente ao seu funeral, "passou os quarenta e cinco anos seguintes inventando o telégrafo. [...] E desenvolvendo o código Morse" (Distância, p. 9-10), na tentativa de que mais ninguém passasse por aquilo que ele viveu -, ao dia em que muitos nova-iorquinos quase enlouqueceram quando em uma manhã de novembro de 1874 uma alarmante notícia - inventada e publicada pelo jornal New York Herald — trouxe à tona muitos "monstros imaginários", dando uma liçấo "que vale a pena recordar de vez em quando" (Enlouquecidos, p. 245-248), sobretudo diante de uma época em que as fake news estáo ganhando cada vez mais destaque.

Entre as duas histórias, há muitas outras que emocionam, que chocam, que nos atingem de modo peculiar, nos fazendo pensar sobre o ocorrido ou sobre situaçóes semelhantes que aconteceram também em tempos remotos e em outros lugares, distintos daquele que DiMeo descreve, ou que aconteceram recentemente; ou que acontecem ainda hoje, perto de nós, às vezes conosco, nessa sociedade em que muitos governos gostam de se autoproclamar democráticos, ainda que a democracia seja conhecida por poucos e distante de muitos.

Dentre alguns desses casos, que podem se relacionar de uma forma ou de outra, podemos trazer como exemplo o caso dos meninos de 9 anos que morriam simplesmente por serem crianças e por efetuarem um trabalho perigoso demais (Nipper, p. 17-18). De Minik Wallace, um inuíte de 7 anos de idade que vivia em um pequeno vilarejo na 
Groenlândia e viu o pai e outros conterrâneos morrerem quando saíram pela primeira vez de seu lugar de origem, convencidos por homens brancos a partirem para a cidade de Nova York, onde foram apresentados como artefatos e atração exótica, e que seriam estudados por cientistas do Museu de História Natural. Após a morte do pai, ele quis realizar um enterro conforme as tradições de sua cultura, descobrindo anos depois que fizera uma cerimônia sagrada inuíte para um saco de pedras, pois o corpo do pai havia sido mantido no museu, onde cientistas o dissecaram, fizeram estudos com o cérebro e deixaram os ossos em exposição (Algumas palavras para os responsáveis, p. 44-47). Das cobaias utilizadas durante o período da corrida espacial entre os Estados Unidos e a União das Repúblicas Socialistas Soviéticas (Cobaias, p. 103-105). De James Powell e sua mãe, bem como de Odessa Bradford, de Perfecto Bandalan, de Eugene Williams, de Robert Bandy e de outros afro-americanos ou imigrantes esquecidos (Esquecemos, p. 120-122). Da coragem de amar de Charlie Zulu e Anita Corsini (Zulu Charlie Romeu, p. 150-155). Da trágica história de Lucy Bakewell (Um pintor na paisagem, p. 173-181). Do filhote de leão capturado no deserto da Núbia para ser transformado numa das mais conhecidas imagens do cinema - ainda que a imagem não descreva as situaçóes pelas quais ele teve que passar (Vulgo: Leo, p. 198-202). Do simbolismo para a comunidade LGBT do White Horse, o mais antigo bar gay dos Estados Unidos (Um cavalo branco, p. 206210). Das 77 pessoas que se tornaram mais de 8 mil, numa jornada de 500 quilômetros, na busca dos trabalhadores do campo pelo direito de se organizarem em sindicatos para que pudessem exigir dignidade humana (Peregrinar, p. 233-237). Entre tantas outras...

São histórias inspiradoras que nos levam a rever o momento presente por outra perspectiva, a repensar certos conceitos e a valorizar as potencialidades contidas nas ações humanas, sejam elas realizadas por grandes nomes ou por desconhecidos/as, pessoas que se inscrevem na e escrevem a História, tanto quanto aqueles a quem os livros oficiais mais costumam demarcar como os nomes a serem lembrados (ou, como muitas vezes acontece, decorados) para a realização de uma prova, para a escrita de uma redação ou para a encenação de uma peça teatral escolar.

Nesse contexto, $O$ palácio da memória insere-se como uma importante e necessária ferramenta educativa, ao desmistificar acontecimentos históricos e ao contribuir, no âmbito historiográfico, a dar "inteligibilidade ao vivido e ao narrado", como destaca Carla Rodeghero. ${ }^{12}$

O principal ponto de ligação do trabalho de Nate DiMeo com a História Oral se dá por ele trabalhar com memórias, o que Alessandro Portelli ${ }^{13}$ destaca — neste trabalho

12 RODEGHERO, Carla Simone. História oral e história recente do Brasil: desafios para a pesquisa e para o ensino. In: RODEGHERO, Carla Simone; GRINBERG, Lúcia; FROTSCHER, Méri (Orgs.). História oral e práticas educacionais. Porto Alegre: Editora da UFRGS, 2016. p. 61-84. p. 80.

${ }_{13}$ PORTELLI, Alessandro. A filosofia e os fatos. Narração, interpretação e significado nas memórias e nas fontes orais. Tempo, Rio de Janeiro, v. 1, n. 2, p. 59-72, 1996. 
entre a História Oral e a Memória — como um "campo de possibilidades compartilhadas, reais ou imaginárias" (1996, p. 72), ajudando-nos a compreender cada fragmento (cada pessoa, cada ação) desse mosaico que compóe a sociedade humana.

"Dizem que a memória pode ser um parque de diversóes estranho e tortuoso, cheio de viagens em montanha-russa e salas de espelhos deformadores", recorda o cineasta Michael Moore. ${ }^{14}$ Nesse parque de diversóes que ilustra a memória, a força narrativa presente nos casos que DiMeo menciona nos prende na leitura do livro (ou na audição dos podcasts) de modo bastante satisfatório; como se ganhássemos as entradas para uma diversão previamente garantida — diversão que não se traduz somente em entretenimento, mas que faz pensar para além do habitual, promovendo reflexão.

Destarte, esse é o tipo de obra que eu recomendaria para os historiadores de ofício, profissionais, acadêmicos e para aqueles que não são, porém apreciam uma boa narrativa literária e gostam de ler/ouvir histórias. “Tudo que dizemos tem um 'antes' e um 'depois' - uma 'margem' na qual outras pessoas podem escrever", acentuou Stuart Hall. ${ }^{15}$ Essa margem é onde Nate se ancora, utilizando-a com esmero.

Gostaria de finalizar este texto destacando duas questóes: primeiro, parabenizar a editora Todavia pela publicação. Olhando em perspectiva, do ponto de vista qualitativo e deixando de lado os dados referentes

\footnotetext{
${ }^{14}$ MOORE, Michael. Adoro problemas: histórias da minha vida. São Paulo: Lua de Papel, 2011.

${ }^{15}$ HALL, Stuart. A identidade cultural na pós-modernidade. 10. ed. Rio de Janeiro: DP\&A, 2005. p. 41.
}

ao número de exemplares vendidos - que no mercado editorial muitas vezes equivale a dizer se a obra foi ou está sendo um sucesso ou um fracasso — , posso afirmar que essa foi uma aposta significativa, pois permite que diferentes indivíduos (historiadores em formação, profissionais e leigos da área) reconheçam o valor contido nas histórias e no ato de narrar, na experiência que ela possibilita, naquele que talvez seja, como descreve Caetano W. Galindo ao final do livro, "o maior de todos os mecanismos de geração de empatia, de interesse, de comunidade e compaixão. Histórias. Narrativas" (p. 252).

Em segundo lugar, e não menos importante, convém destacar o trabalho de Caetano W. Galindo, responsável por traduzir a obra direto do áudio e apresentar o trabalho aos editores da Todavia. Até o momento, ela está em sua primeira edição impressa em nível mundial — nem em seu país de origem ela foi publicada, pois segundo DiMeo, na entrevista a Fernanda Ezabella mencionada no início do texto, os editores que lhe procuram têm interesse em um livro temático, enquanto ele prefere o formato curto de suas histórias, como faz em seu podcast.

Nate DiMeo, esse colecionador de memórias, ${ }^{16}$ vai encontrando novos fatos e personagens históricos para continuar compondo seu palácio da memória, compartilhando conosco os feitos de pessoas extraordinárias em tempos conturbados. Até o momento, o último podcast, o do episódio 144, foi publicado no dia 21 de junho de

\footnotetext{
${ }^{16}$ Como a revista Piauí o retratou na edição 129 , de junho de 2017, na seção Vozes da América.
} 
2019. Se considerarmos que Nate continua realizando seu trabalho e que a edição da obra impressa reúne 50 de suas histórias, ainda há um bom número de casos a serem trabalhados e, quem sabe, publicados em edições futuras. Que as portas do palácio se mantenham abertas para nós!

\section{Referências}

ALBERTI, Verena. O lugar da história oral: o fascínio do vivido e as possibilidades de pesquisa. In: ALBERTI, Verena. Ouvir contar: textos em história oral. Rio de Janeiro: Editora FGV, 2004. p. 13-43.

BALANDIER, Georges. $O$ dédalo: para finalizar o século XX. Rio de Janeiro: Bertrand Brasil, 1999.

BENJAMIN, Walter. Magia e técnica, arte e politica: ensaios sobre literatura e história da cultura. São Paulo: Brasiliense, 2012. (Obras Escolhidas, v. 1)

CALVINO, Italo. Seis propostas para o próximo milênio: liçóes americanas. São Paulo: Companhia das Letras, 1990.

DELGADO, Lucília de Almeida Neves. Memória e história: multiplicidade e singularidade na construção do documento oral. Cadernos CERU, série 2, n. 12, p. 23-30, 2001. p. 24. Disponível em: https://www.revistas.usp.br/ceru/article/ view/75083/78649. Acesso em: março 2018.
DIMEO, Nate. O palácio da memória. Tradução de Caetano W. Galindo. 1. edição. São Paulo: Todavia, 2017. 256 p.

EZABELLA, Fernanda. Ex-repórter de rádio, Nate Dimeo cria podcast que vai virar livro no Brasil. Folha, Los Angeles, 30 de julho de 2017. Disponível em: http://www1.folha. uol.com.br/serafina/2017/08/1904465-exreporter-de-radio-nate-dimeo-cria-podcastque-vai-virar-livro-no-brasil.shtml. Acesso em: abril 2018.

HALL, Stuart. A identidade cultural na pósmodernidade. 10. ed. Rio de Janeiro: DP\&A, 2005.

MOORE, Michael. Adoro problemas: histórias da minha vida. São Paulo: Lua de Papel, 2011.

PORTELLI, Alessandro. A filosofia e os fatos. Narração, interpretaçáo e significado nas memórias e nas fontes orais. Tempo, Rio de Janeiro, v. 1, n. 2, p. 59-72, 1996.

RODEGHERO, Carla Simone. História oral e história recente do Brasil: desafios para a pesquisa e para o ensino. In: RODEGHERO, Carla Simone; GRINBERG, Lúcia; FROTSCHER, Méri (Orgs.). História oral e práticas educacionais. Porto Alegre: Editora da UFRGS, 2016. p. 61-84.p. 80.

YUKA, Marcelo. Sua relação especial com o corpo. TEDxSudeste, 30 out. 2010. Disponível em: https://www.youtube.com/ watch?v=WLIN_Xf4CFk. Acesso em: abril 2018. 